\title{
Education Research: Difficult conversations in neurology
}

\section{Lessons learned from medical students}

Monica E. Lemmon, MD, Charlene Gamaldo, MD, Rachel Marie E. Salas, MD, Ankita Saxena, MD, Tiana E. Cruz, Renee D. Boss, MD, and Roy E. Strowd, MD

Neurology ${ }^{\otimes}$ 2018;90:93-97. doi:10.1212/WNL.0000000000004794

\section{Abstract}

\section{Objective}

To characterize features of medical student exposure to difficult conversations during a neurology core clerkship.

\section{Methods}

This was a cross-sectional concurrent nested mixed methods study, and all students rotating through a required neurology clerkship between 2014 and 2015 were enrolled. Data collection included an electronic communication tracker, baseline and end-of-clerkship surveys, and 4 facilitated focus groups. Students were asked to log exposure to patient-clinician conversations about (1) new disability, (2) poor prognosis, (3) prognostic uncertainty (4), terminal diagnosis, and $(5)$ end-of-life care.

\section{Results}

A total of 159 students were enrolled and 276 conversations were tracked. Most (70\%) students observed at least 1 difficult conversation, and conversations about poor prognosis, new disability, and prognostic uncertainty were most commonly logged. At clerkship end, most students (87\%) desired additional bedside training in communication skills. Exposure to one of the predefined conversation types did not improve student perceived preparedness to lead difficult conversations in the future. In focus groups, students noted that the educational value of observation of a difficult conversation could be optimized with preconversation planning and postconversation debriefing.

\section{Conclusions}

Difficult conversations are common in neurology, and represent a valuable opportunity to provide communication skills training on the wards. Future curricula should consider ways to leverage these existing opportunities to enhance communication skills training.

\author{
Correspondence \\ Dr. Lemmon \\ monica.lemmon@duke.edu
}


Enhanced communication has been recognized as an effective strategy to improve patient safety and care quality. ${ }^{1}$ Although communication and interpersonal skills development is a central tenet of medical education ${ }^{2,3}$ and is heavily represented in 12 of 13 entrustable professional activities expected of graduating medical students, ${ }^{4}$ few studies have evaluated how medical students gain communication skills on the wards.

The neurology discipline frequently involves the delivery of complex and difficult news to patients and families; the neurology clerkship provides medical students an opportunity to experience these interactions first hand. Here, we aimed to define and characterize features of medical students' exposure to difficult conversations during a neurology core clerkship. We hypothesized that the majority of students rotating through the neurology clerkship would be exposed to at least one difficult conversation, and that exposure alone would be insufficient to improve perceived preparedness to lead such conversations in the future.

\section{Methods}

This was a cross-sectional concurrent nested mixed methods study at a single institution. ${ }^{5}$ All medical students rotating through a required 4-week neurology clerkship were eligible. The clerkship includes 2 weeks each in the inpatient wards and outpatient clinics. During their inpatient time, students spend 2 weeks on the pediatric neurology, consult neurology, stroke neurology, or general neurology service. During their outpatient time, students rotate through clinics in general adult and pediatric neurology, as well as specialty clinics, such as epilepsy, neuromuscular, neuro-oncology, movement disorders, sleep medicine, and neuroimmunology. The study was reviewed and exempted by the institutional review board. Quantitative data collection included (1) an electronic communication tracker and (2) baseline and end-of-clerkship surveys. Qualitative data were collected from open-ended survey items and 4 student focus groups.

\section{Communication tracking}

To standardize reporting, students logged 5 predefined difficult conversations. Topics were selected and refined by the study team in consensus and included (1) new disability, (2) poor prognosis, (3) prognostic uncertainty, (4) terminal diagnosis, and (5) end-of-life care. Online communication tracking was integrated into an existing electronic patient log. Students tracked the date of encounter, where the conversation occurred (inpatient vs outpatient), who led or supervised the conversation (resident vs faculty), and the primary conversation topic (i.e., death, poor prognosis, uncertainty). Students participated in a 30-minute introductory lecture during clerkship orientation in which the 5 predefined difficult conversation types were introduced and communication tracking explained.

\section{Surveys}

Baseline and follow-up surveys were adapted from an existing communication intervention. ${ }^{6}$ These surveys asked students to indicate previous communication skills instruction, perceived preparedness for the 5 conversation types, and perceived need for additional instruction.

\section{Focus groups}

Four rotations of students participated in facilitated focus groups led by 2 study investigators (M.E.L., R.E.S.). The focus group guide was developed to expand on quantitative data and targeted student perceptions of (1) exposure to difficult conversations and (2) additional opportunities within the clerkship for communication skills training. A combination of transcriptions and field notes were used for analysis. Focus group content was analyzed using a directed content analysis approach. ${ }^{7}$

\section{Statistical analysis}

Statistical analysis was performed using Stata/SE v14 (StataCorp, College Station, TX). Descriptive statistics were used to compare baseline and follow-up survey data, with responses analyzed as categorical (5-point Likert) variables. Unpaired Student $t$ tests were used to compare continuous variables; $\chi^{2}$, Fisher exact test, and analysis of variance for categorical variables.

\section{Results}

\section{Student inclusion in difficult conversations on the neurology wards}

They [team and patient] quietly talked and I actually stayed away from it, because the intimacy stressed me out. I didn't know if it was even appropriate for me to be there.

$$
\text { -Student }
$$

A total of 159 students were enrolled between 2014 and 2015; 276 conversations were tracked. Over $70 \%$ of students tracked at least one conversation (table 1). The majority occurred in the inpatient setting and were led by faculty. Conversations about poor prognosis were the most commonly tracked, followed by new disability and prognostic uncertainty. Overall, students tracked a mean of $1.8 \pm 2.5$ conversations with fourthyear students $(3.7 \pm 4.4)$ tracking significantly more compared to second- $(1.3 \pm 1.5)$ or third-year students $(1.4 \pm 1.8, p=$ $0.001)$.

In focus groups, students confirmed that these conversations were common, and admitted underreporting due to time burden. Students described barriers to inclusion in difficult conversations: feeling unsure if and how they should ask to be included, fear that their involvement may compromise patient care, and concern that their presence would undermine the intimacy of a patientclinician conversation. Some students perceived that they had been purposefully excluded from conversations, due to faculty or resident concerns that these may be unpleasant for the student (table e-1, links.lww.com/WNL/A19).

\section{Effect of exposure to difficult conversations: Missed opportunities}

I think debriefing and being able to talk about these instances will... I feel like I'll be more comfortable when I see it again rather than just being put in a shocked experience and it dissipating after that. 
Table 1 Demographics and communication tracking in the neurology clerkship

\begin{tabular}{ll}
\hline Demographics & $\begin{array}{l}\text { Values } \\
\text { (total } \mathrm{n}=159)\end{array}$ \\
\hline Age, $\mathrm{y}$, mean (SD) & $26.4(2.6)$ \\
\hline Male, $\mathrm{n}(\%)$ & $81(51)$ \\
\hline Medical school years, $\mathrm{n}(\%)$ & $35(22)$ \\
\hline 2 & $97(61)$ \\
\hline 3 & $27(17)$ \\
\hline 4 & \\
\hline Communication tracking & $117(74)$ \\
\hline Students tracking at least 1 difficult conversation, $\mathrm{n}(\%)$ & $1.8(2.5)$ \\
\hline Average difficult conversations tracked, mean (SD) & $1.3(1.5)$ \\
\hline Year 2 & $1.4(1.8)$ \\
\hline Year 3 & $3.7(4.4)$ \\
\hline Year 4 & $79(29)$ \\
\hline Conversation setting, $\mathrm{n}(\%)$ & $201(73)$ \\
\hline Inpatient & $7(3)$ \\
\hline Outpatient & \\
\hline Conversation leader, $\mathrm{n}(\%)$ & \\
\hline Faculty & \\
\hline Resident & \\
\hline Other & \\
\hline
\end{tabular}

Students tracking difficult conversations, $\mathrm{n}(\%)$

\begin{tabular}{lc}
\hline New disability & $48(30)$ \\
\hline Poor prognosis & $73(46)$ \\
\hline Uncertainty & $45(28)$ \\
\hline Terminal diagnoses & $14(9)$ \\
\hline End of life & $20(13)$ \\
\hline Other & $21(13)$ \\
\hline
\end{tabular}

Though students generally felt more prepared at clerkship end to lead future conversations (all $p<0.001$ ), students who reported exposure to difficult conversations were no more likely to feel prepared than those who did not (all $p>0.38$ ). At clerkship end, approximately half of students reported feeling prepared or very prepared (4 or 5 on 5-point Likert) to lead conversations about neurologic prognosis or new disability; a minority $(<8 \%)$ felt very prepared. While fewer students at clerkship end felt the need for additional didactic instruction (49 vs $67 \%, p<0.001$ ) and interactive classroom instruction ( 61 vs $81 \%, p=<0.001$ ), the desire for additional bedside instruction was high at baseline and remained unchanged ( $85 \%$ vs $87 \%, p=0.47)$.
In focus groups, students offered insights into why observing a difficult conversation did not alone improve their preparedness to lead future conversations. They identified preconversation planning as a valuable and often missed educational opportunity. Planning meetings prior to difficult conversations were rare; $10 \%-20 \%$ of focus group participants reported having at least one of these types of encounters. When they did occur, they were typically about logistics-who would speak, which team members would attend-and rarely about meeting content or how to convey information. Those students who did have such encounters felt that a preconversation plan helped keep team members on the same page and allowed them to "come together and conclude what we're presenting to the family."

Students identified debriefing sessions or postconversation reflection as educationally valuable, but infrequent (10\%-20\% of focus group participants) and cursory. Several students described discussing a conversation informally with members of a team, often when walking from one clinical space to the next; this was typically an information transfer and did not include discussion of how information from the team was relayed to the patient or family. The few students who experienced a debriefing session felt it helped them process emotions and gave them a framework to structure future encounters.

\section{Opportunities to enhance communication skills instruction: Insights from students}

I got feedback on rounds all the time about the physical exam or the history — what to do next time you encounter this, how to do this better, what you did wrong, those sorts of things. It just wasn't focused on conversations.

-Student

Students offered insight into future clinical communication skills curriculum development. While they valued how other educational content (e.g., performing the neurologic examination or a lumbar puncture) was incorporated into the routine work day, several students wondered why communication skills training could not be similarly taught "in the moment." Students who reported influential communication encounters on prior rotations remarked that just a single high-yield conversation bookmarked with preconversation planning and postconversation debriefing had a substantial effect on their future practice.

Students suggested that communication skills development target clinicians at all levels of training, including students, residents, and faculty. Students noted that much of their direct instruction in communication skills came from residents, who often set the team's tone. Students also noted that certain faculty members were better equipped to teach communication skills than others, and suggested a "top down and bottom up" strategy toward communications skills curriculum development that was inclusive of faculty and resident training activities. 


\section{Discussion}

At the end of medical school, students should be prepared to effectively communicate complex and difficult information to patients and families. Our results suggest that the neurology clerkship offers valuable opportunities for students to learn these skills through direct observation of complex patientclinician communication, and that clinical communication skills training would be welcomed by medical students. Students appreciated being in the room during difficult communication encounters, but highlighted that both their education and clinical care could be improved by regular team planning and debriefing.

The American Academy of Neurology recently outlined a framework for communication skills attainment in medical school curricula. ${ }^{3}$ As next steps, medical educators in neurology should consider building on communication skills training models in other disciplines ${ }^{8,9}$ to create tailored curricula that address the issues that commonly arise in neurology. Specific target areas might include (1) communication of neurologic prognosis and prognostic uncertainty, (2) facilitation of shared decision-making, and (3) interprofessional team communication. Partnering with educators throughout the medical school curriculum, in both clinical and preclinical years, can ensure students receive ongoing, longitudinal communication skills instruction. Medical students in their final year tracked significantly more conversations than those in their second and third years, which may suggest that more seasoned medical students are more likely to be included in, or seek out, difficult conversations. Efforts should be made to ensure students have opportunities to observe complex communication encounters throughout their clinical training.

This descriptive study is limited by reliance on student recall and perceptions of preparedness; future work should include objective measures of skill attainment. Mastery of patientclinician communication likely requires years; the short duration of this study limited our ability to completely characterize long-term change in communication preparedness and highyield encounters on prior rotations. Conversation type was predefined and additional conversation types (e.g., error disclosure) are not captured. Focus groups revealed significant underreporting, which limited our ability to detect the true effect of conversation exposure. In addition, our survey methodology risks social desirability bias and may have led students to answer affirmatively, which may explain why quantitative results showed global improvement in preparedness, while focus groups contradicted this finding. Nonetheless, this study offers a necessary first step in defining and characterizing existing opportunities for communication skills instruction on the wards. Future directions should include assessment of difficult conversations across the clinical curriculum, instructor attitudes toward communication skills training, and educational interventions targeting debriefing and preconversation planning.
Communication skills are a critical competency expected of medical students prior to graduation. Our results offer a first step in defining the educational opportunities that exist to enhance communication skills instruction. These existing clinical opportunities can be leveraged to enhance medical student education in communication skills.

\section{Author contributions}

Dr. Lemmon was involved in manuscript conception and design, data collection and analysis, drafted and critically revised the manuscript, and approved the final manuscript as written. Dr. Gamaldo was involved in manuscript conception and design, critically revised the manuscript, and approved the final manuscript as written. Dr. Salas was involved in manuscript conception and design, critically revised the manuscript, and approved the final manuscript as written. A. Saxena was involved in data collection and analysis, critically revised the manuscript, and approved the final manuscript as written. T.E. Cruz was involved in manuscript conception and design, data collection, critically revised the manuscript, and approved the final manuscript as written. Dr. Boss was involved in manuscript conception and design and data analysis, critically revised the manuscript, and approved the final manuscript as written. Dr. Strowd was involved in manuscript conception and design, data collection and analysis, drafted and critically revised the manuscript, and approved the final manuscript as written.

\section{Study funding}

M.E.L. and R.E.S. have received support from the American Academy of Neurology's Medical Education Research Training Fellowship.

\section{Disclosure}

M. Lemmon has received salary support from the American Academy of Neurology's Medical Education Research Fellowship training grant and is currently supported by the National Palliative Care Research Center. C. Gamaldo has entered into an agreement with UpToDate, Inc. and has been paid royalties for her contribution of medical articles for this publication. She has received less than $\$ 400$. R. Salas has entered into an agreement with UpToDate, Inc. and has been paid royalties for her contribution of medical articles for this publication. She has received less than $\$ 400$. A. Saxena and T. Cruz report no disclosures relevant to the manuscript. R. Boss is supported through the Cambia Sojourns Scholars Leadership Award through the Cambia Health Foundation. R. Strowd has received salary support from the American Academy of Neurology's Medical Education Research Grant and Medical Education Research Fellowship Training Grant. Dr. Strowd serves as the Deputy Section Editor for the Resident \& Fellow Section of Neurology. Go to Neurology.org/N for full disclosures.

\section{References}

1. Ball JR, Balogh E. Improving diagnosis in health care: highlights of a report from the National Academies of Sciences, Engineering, and Medicine. Ann Intern Med 2016; 164:59-61. 
2. Peltier WL. Core competencies in neurology resident education: a review and tips for implementation. Neurologist 2004;10:97-101.

3. Merlin LR, Horak HA, Milligan TA, Kraakevik JA, Ali II. A competency-based longitudinal core curriculum in medical neuroscience. Neurology 2014;83: $456-462$.

4. Englander R, Flynn T, Call S, et al. Toward defining the foundation of the MD degree: core entrustable professional activities for entering residency. Acad Med 2016;91: 1352-1358.

5. Creswell JW, Creswell JW. Qualitative Inquiry and Research Design: Choosing Among Five Approaches, 3rd ed. Los Angeles: SAGE Publications; 2013.
6. Boss RD, Urban A, Barnett MD, Arnold RM. Neonatal Critical Care Communication (NC3): training NICU physicians and nurse practitioners. J Perinatol 2013;33: 642-646.

7. Miles MB, Huberman AM. Qualitative Data Analysis: An Expanded Sourcebook, 2nd ed. Thousand Oaks, CA: Sage Publications; 1994

8. Back AL, Arnold RM, Baile WF, et al. Efficacy of communication skills training for giving bad news and discussing transitions to palliative care. Arch Intern Med 2007; 167:453-460

9. Arnold RM, Back AL, Barnato AE, et al. The Critical Care Communication project: improving fellows' communication skills. J Crit Care 2015;30:250-254.

\section{Subspecialty Alerts by E-mail!}

Customize your online journal experience by signing up for e-mail alerts related to your subspecialty or area of interest. Access this free service by clicking on the "My Alerts" link on the home page. An extensive list of subspecialties, methods, and study design choices will be available for you to choose from-allowing you priority alerts to cutting-edge research in your field!

\section{Neurology in the Spotlight at 2018 Annual Meeting in Los Angeles}

Registration is now open for the totally flexible, dynamic 2018 Annual Meeting. We'll be shining the spotlight on neurology and what you need to excel in your career. Look for the latest science, education, and networking you won't find anywhere else when the biggest names in neurology and neuroscience convene in Los Angeles April 21 through 27. Learn more and register now at AAN.com/view/AM18.

\section{Disputes \& Debates: Rapid online correspondence}

The editors encourage comments on recent articles through Disputes \& Debates:

Access an article at Neurology.org/ $N$ and click on "COMMENT" beneath the article header. Responses will be posted within 3 business days.

Before submitting a comment to Disputes \& Debates, remember the following:

- Disputes \& Debates is restricted to comments about studies published in Neurology within the last eight weeks

- Read previously posted comments; redundant comments will not be posted

- Your submission must be 200 words or less and have a maximum of five references; reference one must be the article on which you are commenting

- You can include a maximum of five authors (including yourself) 


\section{Neurology}

\section{Education Research: Difficult conversations in neurology: Lessons learned from medical students}

Monica E. Lemmon, Charlene Gamaldo, Rachel Marie E. Salas, et al. Neurology 2018;90;93-97

DOI 10.1212/WNL.0000000000004794

\section{This information is current as of January 8, 2018}

\section{Updated Information \& Services}

References

Citations

Subspecialty Collections

Permissions \& Licensing

Reprints including high resolution figures, can be found at: http://n.neurology.org/content/90/2/93.full

This article cites 7 articles, 1 of which you can access for free at: http://n.neurology.org/content/90/2/93.full\#ref-list-1

This article has been cited by 3 HighWire-hosted articles: http://n.neurology.org/content/90/2/93.full\#\#otherarticles

This article, along with others on similar topics, appears in the following collection(s):

Methods of education

http://n.neurology.org/cgi/collection/methods_of_education

Prognosis

http://n.neurology.org/cgi/collection/prognosis

Information about reproducing this article in parts (figures,tables) or in its entirety can be found online at:

http://www.neurology.org/about/about_the_journal\#permissions

Information about ordering reprints can be found online:

http://n.neurology.org/subscribers/advertise

Neurology ${ }^{\circledR}$ is the official journal of the American Academy of Neurology. Published continuously since 1951 , it is now a weekly with 48 issues per year. Copyright Copyright @ 2018 American Academy of Neurology. All rights reserved. Print ISSN: 0028-3878. Online ISSN: 1526-632X.

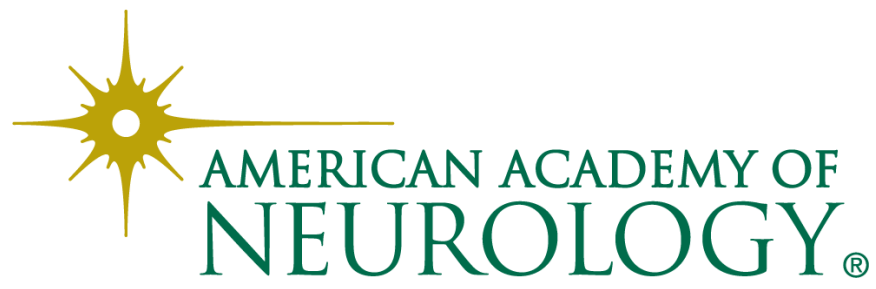

